\title{
Quantificação e qualificação das alterações em Áreas de Preservação Permanente de um trecho do Rio das Mortes, Mato Grosso, Brasil
}

\author{
Handerson Batista de Castro ${ }^{1 \%}$ \\ Leandro Schlemmer Brasil ${ }^{1}$ \\ Márcia Luiza Santos ${ }^{1}$ \\ Marco Bruno Xavier Valadão ${ }^{1}$ \\ Nubia França da Silva Giehl ${ }^{1}$ \\ Sergio Lopes de Oliveira ${ }^{1}$ \\ Cesar Enrique de Melo ${ }^{1,2}$ \\ Universidade do Estado de Mato Grosso \\ ${ }^{1}$ PPG em Ecologia e Conservação \\ ${ }^{2}$ Laboratório de Ictiologia e Limnologia \\ BR 158, Caixa Postal 08, CEP 78690-000, Nova Xavantina, MT - Brasil \\ * Autor para correspondência \\ handersoncastro@gmail.com
}

Submetido em 26/11/2012

Aceito para publicação em 28/06/2013

\section{Resumo}

O objetivo do presente trabalho foi verificar alterações qualitativas e quantitativas nas Áreas de Preservação Permanente (APPs) de um trecho de $20 \mathrm{~km}$ do Rio das Mortes no Município de Nova Xavantina, Mato Grosso. Para o cálculo das áreas utilizou-se de recursos de baixo custo: Google Earth (GE), fotografias Aéreas de Pequeno Formato (FAPEF) e o software (GEPath). Adicionalmente, foi realizada uma visita em campo para distinção quanto ao uso da terra. Foram analisados 457,02 ha de APP, sendo que 15,6\% encontravam-se alteradas e subdivididas em 45 fragmentos. A introdução de pastagens para o gado bovino foi a principal causa das alterações, sendo que entre os 19 pontos visitados, sete eram pastagens novas, seis em regeneração inicial, quatro em regeneração média e dois eram ocupados por moradias. A degradação foi relacionada significativamente com a proximidade da cidade. As imagens do Google Earth, sobrepostas por FAPEFs, forneceram resultados satisfatórios para a identificação de alterações ambientais, porém a confirmação em campo foi crucial para a determinação das fisionomias.

Palavras-chave: Alteração ambiental; Mata ciliar; Sensoriamento remoto

\section{Abstract}

Quantification and qualification of the alterations in Permanent Preservation Areas in a stretch of Rio das Mortes, Mato Grosso, Brazil. The objective of the present work was to determine the qualitative and quantitative alterations in the Permanent Preservation Areas (PPA) of a 20-km stretch of Rio das Mortes 
in the Municipality of Nova Xavantina, Mato Grosso. The areas were determined utilizing low-cost resources: Google Earth (GE), small format aerial photographs (SFAP) and GE Path software. Additionally, a field visit was made to distinguish the use of the land. A total of 457.02 ha of the PPA were analyzed, showing that $15.6 \%$ were altered and subdivided into 45 fragments. The introduction of pastures for cattle was the principal cause of the alterations, where among the 19 points visited, seven were new pastures, six in initial regeneration, four in intermediate regeneration and two occupied by housing. Degradation was significantly related to the proximity of the city. Google Earth images, superimposed by SFAPs, provided satisfactory results for the identification of environmental alterations, but confirmation in the field was crucial for the determination of the physiognomies.

Key words: Environmental changes; Remote sensing; Riparian forest

\section{Introdução}

O Cerrado é considerado um importante bioma do Brasil. A formação ecológica Campo-Cerrado abrange cerca de 55\% da área do Centro-Oeste. Desta percentagem grande parte abrange o estado do Mato Grosso (CARVALHO, 2001), sendo aproximadamente $34 \%$ do seu território domínio de Cerrado (PIAIA, 1999).

Atualmente mais de $38 \%$ da área do estado de Mato Grosso foi desmatada e destinada ao agronegócio (SEPLAN, 2010). Embora essas alterações ambientais tenham colocado o estado como um dos maiores produtores agrícolas do Brasil, pouco se sabe sobre os impactos da atividade agropecuária sobre seus biomas, e, principalmente, sobre seus cursos d'água, os quais representam algumas das bacias hidrográficas mais importantes do país (LIMA; SILVA, 2008). Uma das bacias hidrográficas mais importantes dessa região é a bacia Araguaia-Tocantins, da qual, o Rio das Mortes é um dos afluentes mais importantes, tanto em volume de água como pelo tamanho da área de drenagem (MELO et al., 2005).

As matas ciliares são formações florestais que acompanham os rios e se destacam por possuir grande importância para manutenção da biodiversidade através dos corredores ecológicos, assim como para a qualidade da água dos mananciais (BARBOSA, 1999). Sua conservação promove a manutenção da qualidade da água dos mananciais e contribui para a redução dos processos erosivos do solo e consequentemente diminui o assoreamento dos cursos d'água (LACERDA; FIGUEIREDO, 2009). Por essas e outras razões estes locais foram determinados como Áreas de Preservação Permanente (APPs) de acordo com o Art. 2o do Código
Florestal Brasileiro (Lei no 4.771, de 15/09/65) ou da mesma forma pela Lei no 12.651 de 25/05/2012 e a Lei Complementar no 38 de 21/11/1995, que institui o Código Ambiental do Estado de Mato Grosso (MEDAUAR, 2009).

Portanto, verificando a importância das APPs como um instrumento de preservação ambiental, muitas técnicas de planejamento ambiental estão sendo estudadas, produzidas e aplicadas para gerenciá-las. Dentre muitas, podemos destacar o desenvolvimento de técnicas de sensoriamento remoto como: software livre Google Earth (GE) e Fotografias Aéreas de Pequeno Formato (FAPEFs) que são utilizados para o monitoramento de uso e ocupação do solo, bem como a ocorrência de eventos de degradação.

O uso de FAPEFs tem sido aplicado devido ao seu baixo custo e pela obtenção de informações com grande resolução temporal e espacial (MENDES-JÚNIOR; AYUP-ZOUAIN, 2004) além de ser um instrumento mais acessível aos interessados em estudos com maior precisão em pequenas áreas (CUNHA et al., 2006). Assim, o objetivo desse trabalho foi aplicar GE e FAPEF para qualificar e quantificar as possíveis alterações em Áreas de Preservação Permanente (APPs) ao longo de um trecho de $20 \mathrm{~km}$ no Rio das Mortes (MT).

\section{Material e Métodos}

\section{Área de estudo}

$\mathrm{O}$ estudo foi conduzido às margens do Rio das Mortes, que nasce na Chapada dos Guimarães e deságua no Rio Araguaia na altura da porção intermediária da Ilha do Bananal (SILVA et al., 2007). 
As áreas amostradas foram estabelecidas dentro dos limites do município de Nova Xavantina, que conta com aproximadamente 20.000 habitantes é o maior núcleo urbano estabelecido às margens desse rio (SEPLAN, 2010), entre as coordenadas S14\%46'17.2" W052 36'42.5” e S 1439'33.9” W 052 30’31.0" (Figura 1).

FIGURA 1: Distribuição dos pontos de amostragem nas APPs do Rio das Mortes, Nova Xavantina, Mato Grosso, 2012.

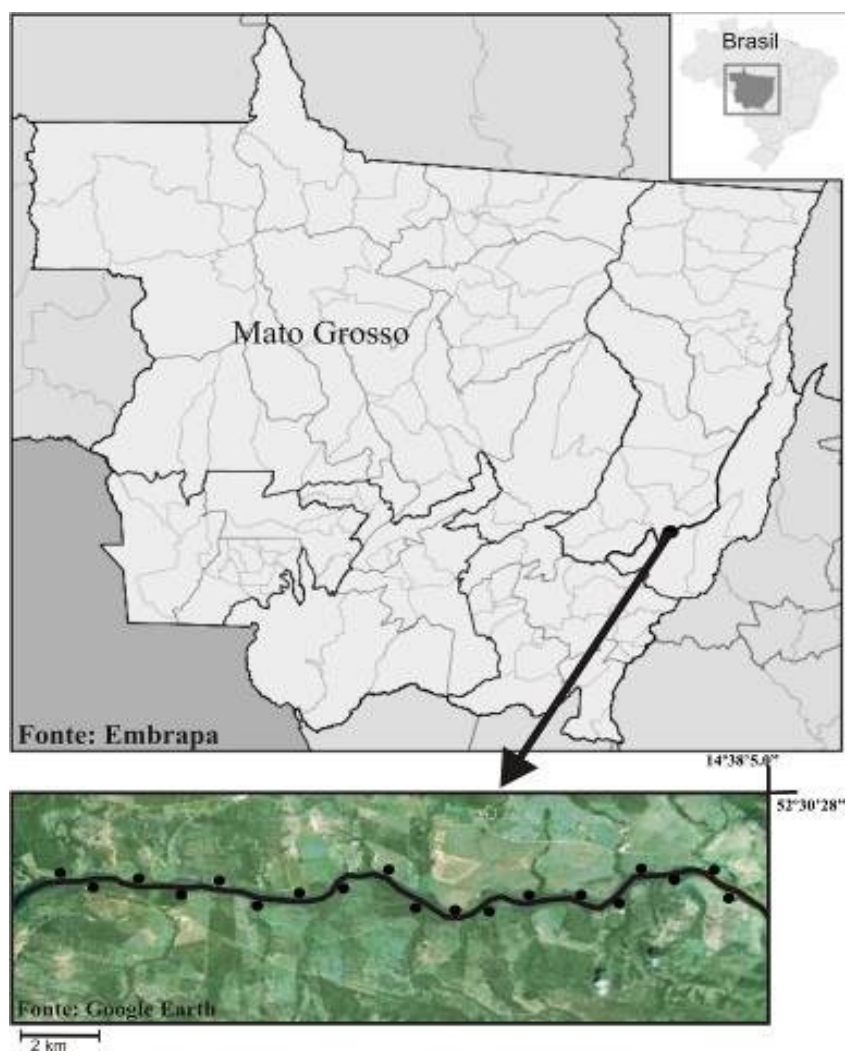

\section{Obtenção das FAPEFs}

As FAPEFs foram obtidas por meio de uma máquina digital SONY Cyber-shot DSC R1, com 10.3 MP de resolução, acoplada a um ultraleve tipo Trike Ícaros Adventure SL4, em sobrevôo estabilizado a 600 $\mathrm{m}$ de altura sobre o Rio das Mortes. Cada imagem obtida cobre uma área de aproximadamente 600 x 900 m, com resolução de 10 Megapixels.

\section{Qualificação das áreas de amostragem}

A qualificação das áreas de amostragem foi realizada por meio de visitas in loco, em abril de 2012, onde foram avaliadas as possíveis alterações em 19 áreas de APPs, previamente definidas (Figura 1), com base em imagens GE e FAPEFs. As coordenadas geográficas foram obtidas com o auxílio de GPS Garmin 76S. Nestes locais foi verificado o estado de preservação da vegetação ciliar, estágio de regeneração e tipo de uso do solo em cada ambiente. Em caso de ambiente em regeneração, o mesmo foi classificado em estágio inicial, médio ou avançado (HORN, 1974; DURIGAN; RATTER, 2006; YARRANTON et al. 2007). Os registros foram complementados com fotografias e anotações das características do ambiente.

\section{Quantificação das áreas de amostragem}

No trecho amostrado a largura do Rio das Mortes está entre 100 e $200 \mathrm{~m}$, devendo nesse caso a APP ser delimitada em 100 m. Para marcação dos limites das APPs utilizou-se imagens do GE e a ferramenta de sobreposição de imagens, com a qual inseriu-se as FAPEFs correspondentes a cada imagem de interesse do GE. A marcação dos limites das APPs e áreas alteradas foi realizada com a ferramenta caminho. Para a determinação das áreas dos polígonos correspondentes às APPs ou áreas de alterações, foi utilizado o software GEPath 1.4.4.a., que calcula as áreas com auxílio de coordenadas geográficas geradas no GE e é gratuito.

Para verificar se existe uma relação entre o nível de alteração das APPs e a distância com a zona urbana de Nova Xavantina/MT, foi subdividida a área total em dez parcelas, que abrangeram tanto a margem direita quanto a esquerda do rio (Figura 1). A análise da influência da proximidade do núcleo urbano sobre a porcentagem de área alterada nas parcelas das APPs foi feita utilizando regressão linear simples, segundo Zar (1999).

\section{Resultados e Discussão}

A utilização de FAPEFs se mostrou de grande importância para esse tipo de trabalho. A elevada resolução e o baixo custo das mesmas, associados aos recursos de imagens e georreferenciamento do GE, permitiram delimitar as áreas de APPs e áreas alteradas, com elevado grau de precisão (Figura 2). 
FIGURA 2: APP do Rio das Mortes, com perímetro da área degradada em amarelo: (A) FAPEF sobre imagem do Google Earth (B) Imagem Google Earth.

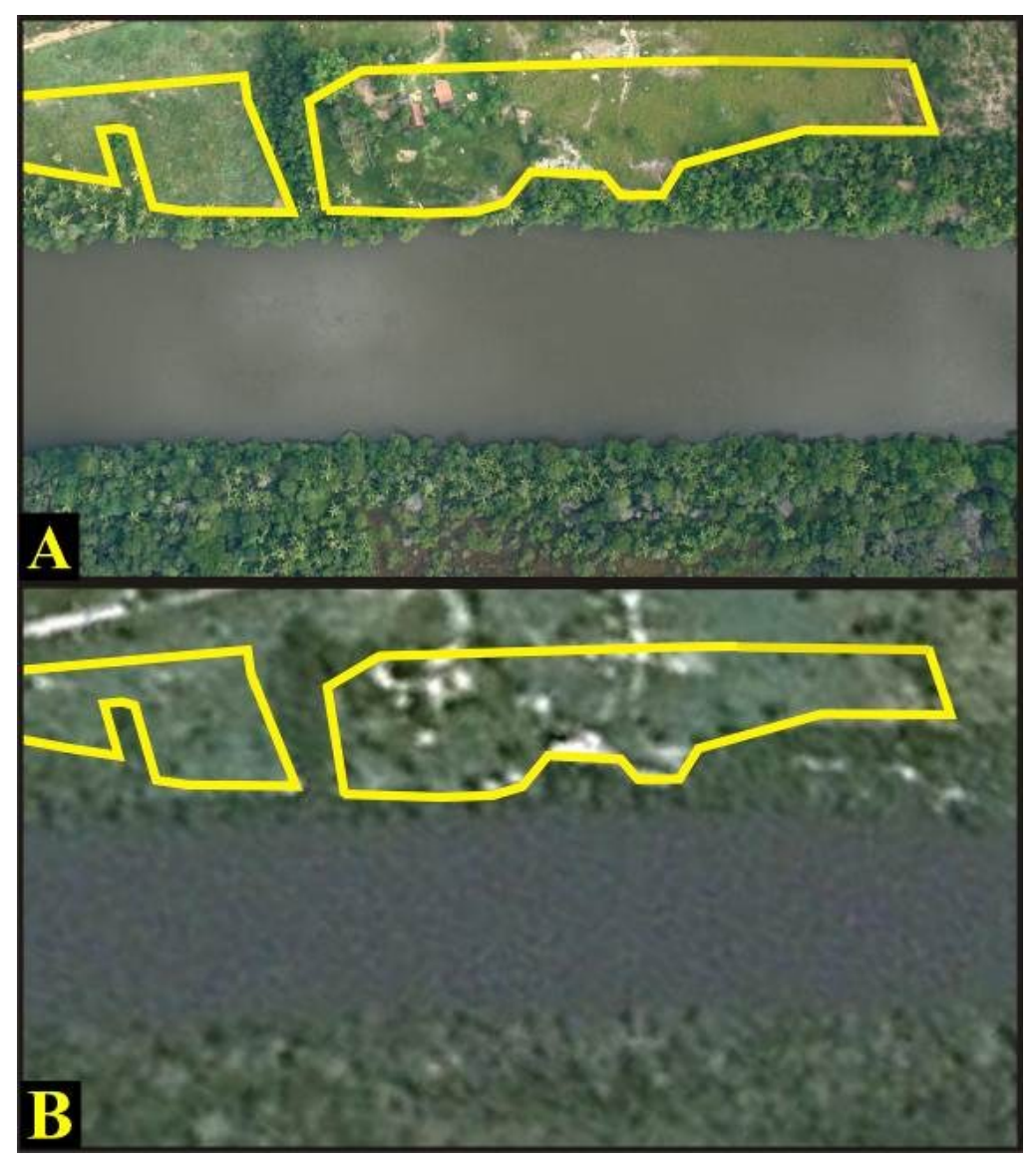

Foram identificados 45 pontos de desmatamento nas APPs ao longo da área de estudo. Isso indica que os proprietários das terras cortadas pelo Rio das Mortes no trecho estudado descumprem a legislação ou a desconhecem, o que acarreta um prejuízo ao cumprimento da função das matas ciliares para a conservação dos rios e da própria biodiversidade, essas formações vegetais representam os ambientes mais diversos do Cerrado (OLIVEIRA; FELFILI, 2005).

$\mathrm{Na}$ área de estudo desse trabalho, conforme o artigo 2oㅡㄴ Lei no 4771/65 ou mesmo conforme o artigo 4ㅇ da Lei no 12.651/12 a área total de APPs deveria ser de 457,02 ha, deste total, 71,24 ha ou $15,6 \%$ estão alterados, dos quais, 29,63 ha à margem direita e 41,61 ha na margem esquerda do Rio das Mortes.

Dentre as ameaças que assolam o Cerrado o desmatamento é uma das mais graves, tanto pelo assoreamento dos rios quanto pelos desgastes do solo (PIAIA, 1999). Esse procedimento, segundo relatório da UNESCO (2000) já havia comprometido cerca de $40 \%$ das matas ciliares do Cerrado.

Quando foram analisadas as áreas alteradas e os registros fotográficos de campo em conjunto, identificaram-se três tipos de vegetação resultante da atividade pecuária: (i) pastagem com predomínio de Brachiaria sp.; (ii) pastagem de Brachiaria sp. com vegetação nativa em estágio inicial de regeneração; e, (iii) pastagem de Brachiaria sp. com vegetação nativa em estágio médio de regeneração. Sendo então, a atividade pecuária a principal responsável pela degradação ambiental em todos os pontos analisados.

Araujo (2010) afirma que, em relação ao efeito do pastoreio bovino na vegetação, existe um efeito negativo no desenvolvimento dos indivíduos da regeneração natural nas áreas de preservação permanente. 
Nos pontos 2, 8, 9, 11, 16, 18 e 19 os solos estão ocupados predominantemente por Brachiaria sp., gramínea exótica destinada para a nutrição de bovinos (Figura 3A). Nestes locais foi observado que as pastagens estavam em bom estado de conservação, porém não respeitando as faixas de APPs estabelecidas por lei, além disso, também podia ser percebido o solapamento das margens, provocadas tanto pela retirada da vegetação nativa das APPs como pelo acesso do gado bovino ao rio.

Nos pontos 4, 5, 7, 10, 13 e 17 a vegetação é composta por herbáceas e/ou outros vegetais com menos de 1,5 $\mathrm{m}$ de altura (Figura 3B), indicando um processo inicial de regeneração da vegetação nativa (LACERDA; FIGUEIREDO, 2009).
Em quatro dos 19 pontos amostrados notou-se a presença de árvores e arbustos o que caracteriza zonas em regeneração média (Figura 3C). Já em sete dos 19 pontos, foram verificados a presença de construções civis dentro das áreas de APPs, representadas principalmente por casas de alvenaria, às quais, invariavelmente estavam associadas outras áreas alteradas para agricultura de subsistência, como mandioca e hortaliças.

De acordo com Rodrigues e Leitão Filho (2000), a combinação de um solo hidromórfico arenoso sob uma mata de brejo caracterizado pela presença de campo limpo, faz parte de um ecossistema extremamente frágil, que poderá se degradar rapidamente se for incorporado ao processo produtivo (Figura 4A-D).

FIGURA 3: Tipo de uso das áreas alteradas em APPs: (A) pastagem nova, com predominância de Brachiaria sp.; (B) pastagem em regeneração inicial; (C) pastagem em regeneração média. Rio das Mortes, Mato Grosso. 2012.

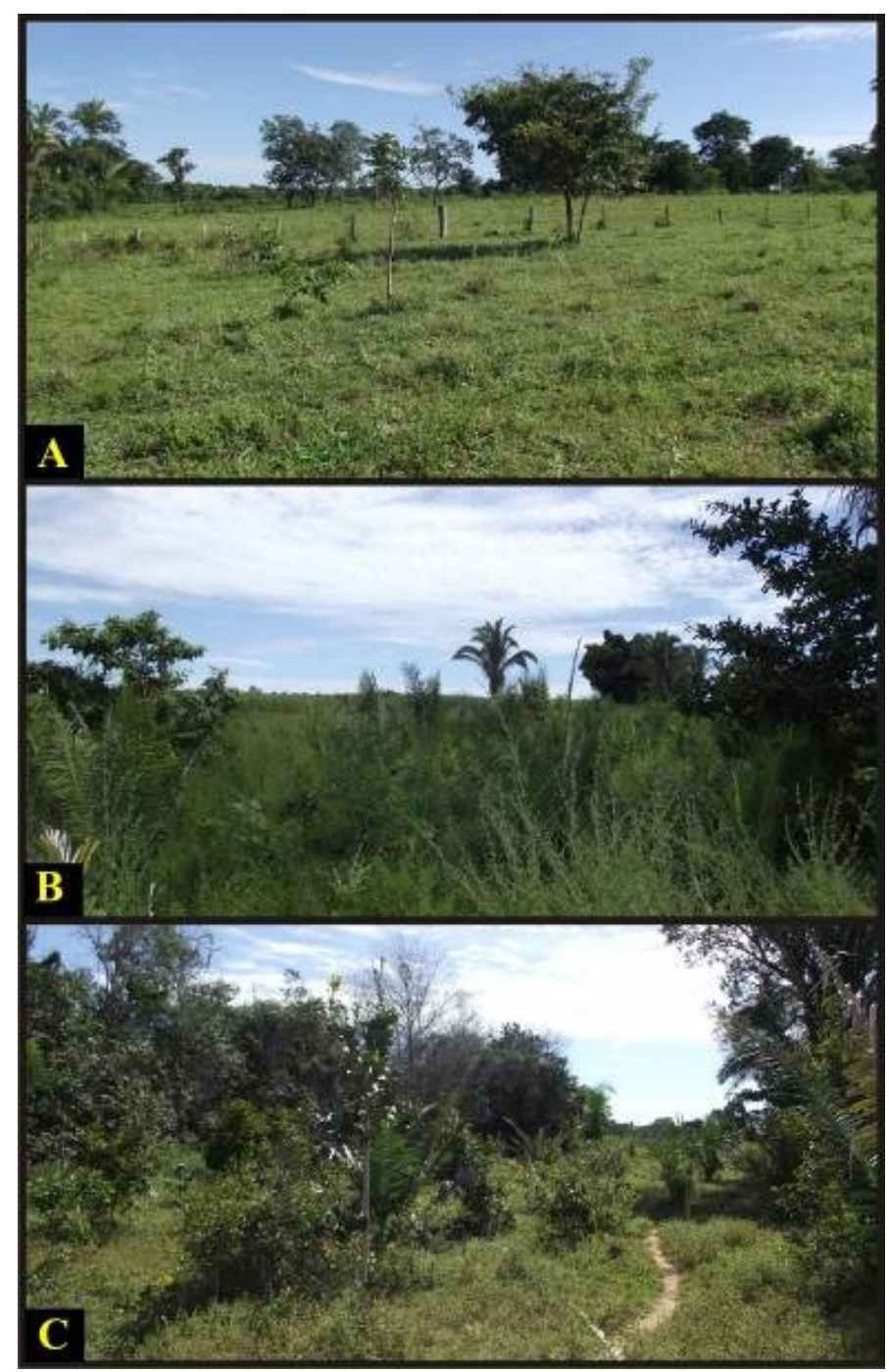


FIGURA 4: (A-B) Imagens FAPEFs, com polígonos em amarelo circundando campo limpo alterado e polígonos em vermelho circundando campo limpo preservado. (C) vista parcial de campo limpo preservado; (D) vista parcial de campo limpo alterado. Rio das Mortes, Mato Grosso, 2012.

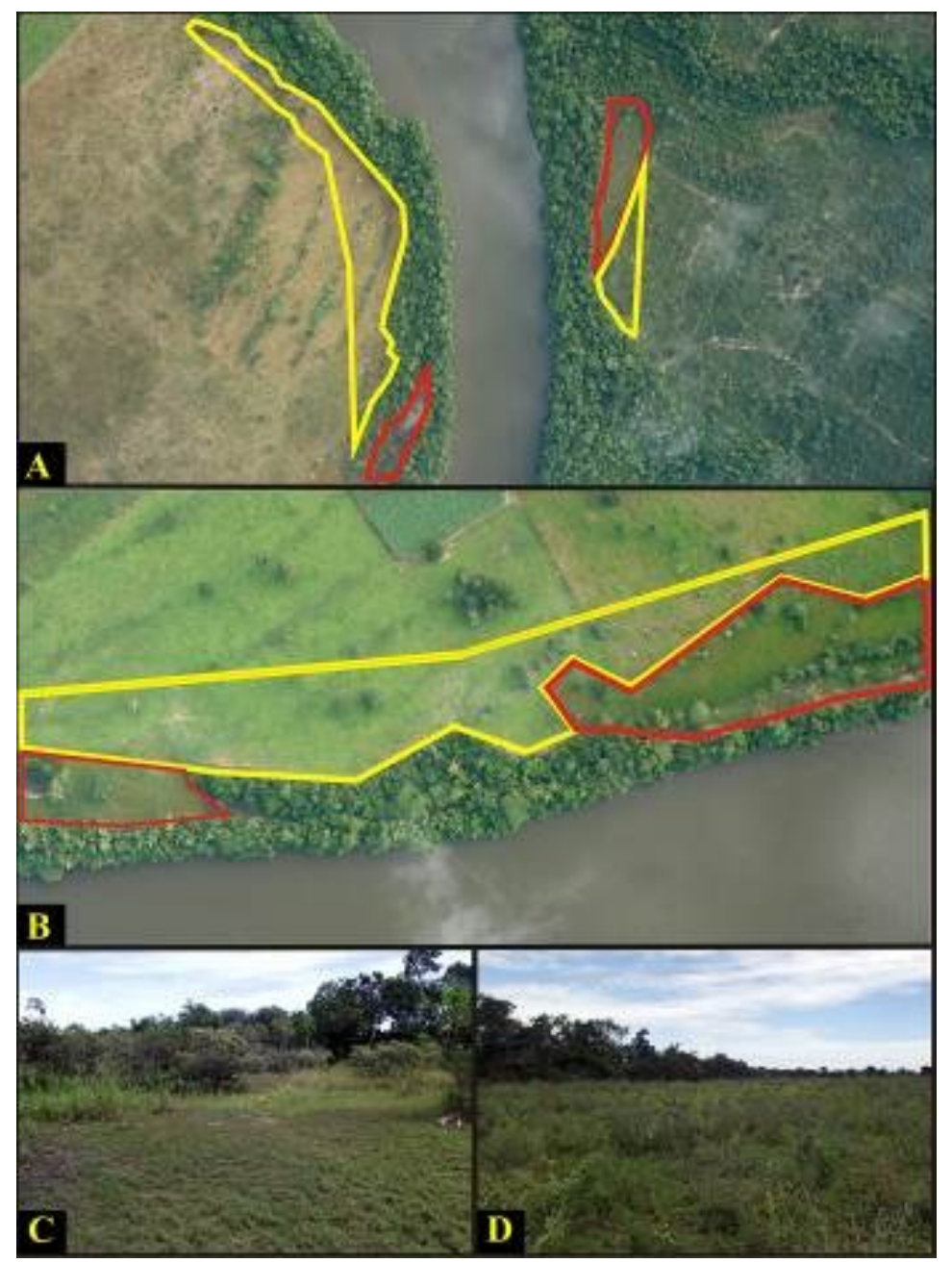

Cunha (1991) menciona que os processos erosivos, são comandados pelos seguintes fatores naturais: volume d'água que atinge o terreno, cobertura vegetal, tipo de solo/rocha, lençol freático e topografia. Neste sentido, em longo prazo a entrada de animais pode potencializar os fatores erosivos. Dias et al. (2001) afirmam que em solo desprotegido de florestas, o pisoteio do gado provoca intenso fluxo de sedimentos à jusante (terras baixas), além de assoreamentos locais.

Ao verificarmos a relação das alterações ambientais encontradas nas APPs com a proximidade ao centro urbano, encontramos uma relação significativa entre quantidade de alteração ambiental e distância da zona urbana de Nova Xavantina-MT (Figura 5). Outros autores corroboram nosso resultado relacionando alteração à proximidade de centros urbanos. Lozinski et al. (2010) constataram alteração em $85 \%$ da área total das APPs de nascentes que ocorrem na área urbana, Haberland et al. (2012) verificaram alterações de solo e parâmetros físicos da água em nascentes próximas da zona urbana e Costa et al. (2011) encontraram um aumento de ocupações irregulares nas APPs próximas da cidade analisada.

De acordo com MMA (2006), nas zonas de APPs na região da sub-bacia do Rio das Mortes o processo de urbanização é crescente, principalmente quando se trata dos projetos de assentamento do INCRA, que disputam espaços destinados às áreas prioritárias para conservação 
FIGURA 5: Regressão da quantidade de áreas alteradas em relação à distância da zona urbana (pontos, ver Tabela 1) Mato Grosso, 2012.

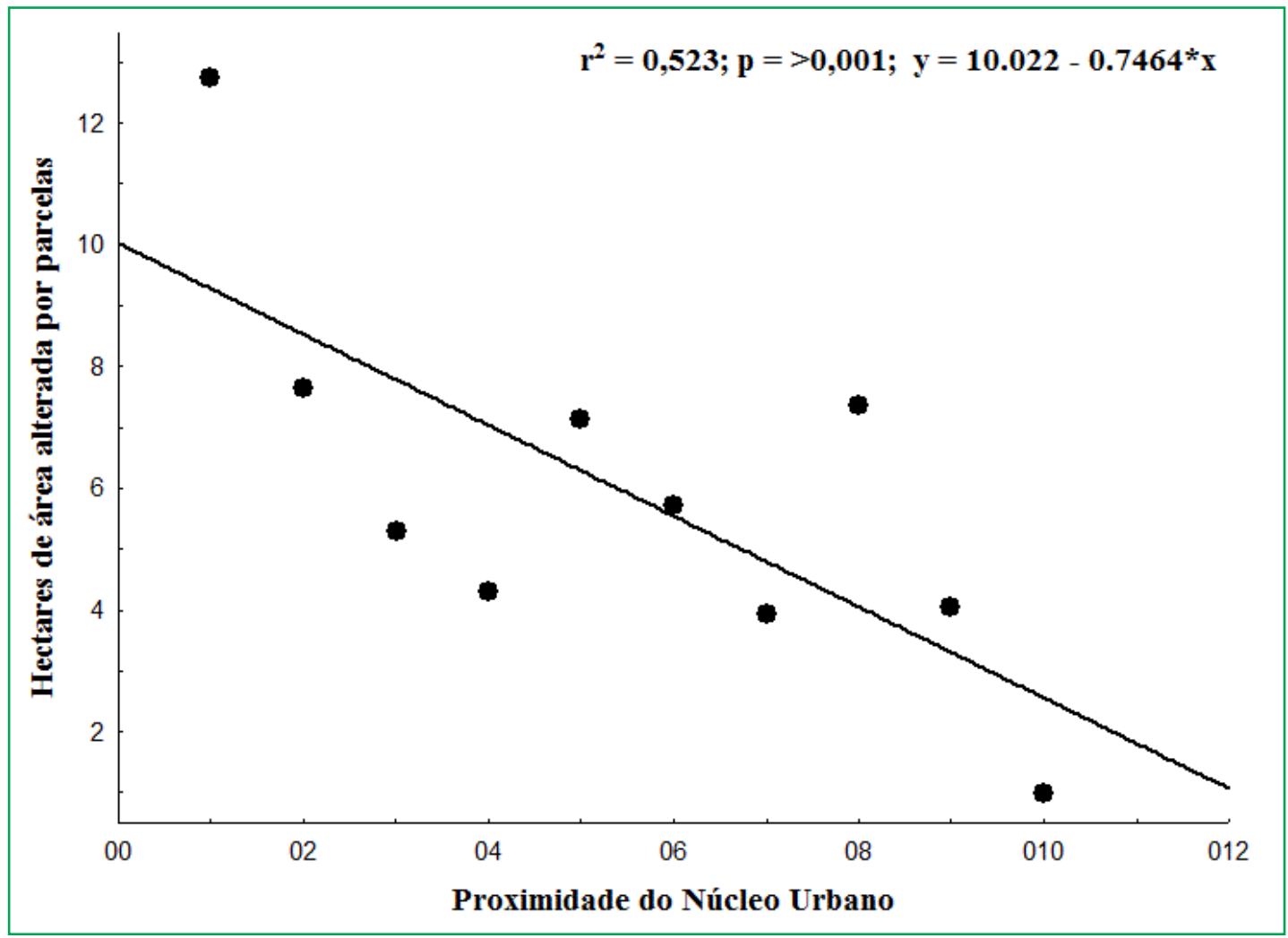

da biodiversidade. Ainda de acordo com o MMA(2006), as principais atividades impactantes na região do Rio das Mortes são a estruturação de hidrovias, o desmatamento, adoção de práticas agropecuárias incorretas e atividades mineradoras.

\section{Qualidade das FAPEFs}

O uso de FAPEFs no presente trabalho se mostrou de grande utilidade, já que as mesmas permitiram a identificação prévia, com riqueza de detalhes das áreas supostamente alteradas de APPs. As imagens disponibilizadas no Google Earth, para a área de estudo em questão, embora de grande utilidade para o georreferenciamento da área, apresentam baixa resolução e nitidez (Figura $2 \mathrm{~A}$ ) se comparadas às FAPEFs (Figura 2B). Isso é corroborado por Daré et al. (2007), que afirmam que as altas resoluções espaciais conseguidas nas FAPEFs possibilitam a identificação de feições com dimensões que, imagens de satélites como as obtidas pela série Land Sat, ou mesmo o CIBERS, não permitiriam.
O uso da sobreposição de FAPEFs e imagens do GE também permitiu apontar o avanço da degradação das áreas amostradas, já que as FAPEFs foram tiradas recentemente (2011), enquanto que as imagens de satélite que o GE disponibiliza para essa região do Rio das Mortes estão no intervalo entre os anos 2000 e 2006.

Além disso, foi verificado que as fotografias aéreas de pequeno formato podem ser utilizadas como uma alternativa de baixo custo e alto nível de resolução para avaliação de áreas degradadas. Essa ferramenta pode ser utilizada como um complemento para as imagens de satélite (CUNHA et al., 2006), que disponibilizadas gratuitamente como é caso do GE, não permitem um detalhamento necessário.

O estudo constatou que $15,6 \%$ da área total de APPs estavam alteradas, a conversão de áreas naturais em capim Brachiaria - resultante da atividade pecuária - foi a principal responsável pela degradação de matas ciliares nesse trecho do Rio das Mortes. A proximidade do núcleo urbano de Nova Xavantina exerce uma influência negativa sobre a conservação dessas áreas. 
Assim, este trabalho demonstra que a proximidade com um centro urbano, mesmo de pequeno porte, influencia diretamente no processo de ocupação irregular de APPs. No entanto, o nível de degradação ainda é relativamente baixo, provocado principalmente por pastagem para bovinos e, as áreas alteradas até o momento, são passíveis de serem recuperadas. As FAPEFs se mostraram de grande utilidade para esse tipo de trabalho e, juntamente com a plataforma gratuita do GE e o software GEPath, formam um conjunto de ferramentas de baixo custo e grande precisão para estudos ambientais de pequena escala, que necessitem de imagens aéreas e georreferenciamento.

\section{Agradecimentos}

Ao Projeto Corredor das Águas, financiado pela Fundação de Amparo à Pesquisa do Estado de Mato Grosso, e à CAPES/FAPEMAT pela concessão das bolsas de estudo aos autores.

\section{Referências}

ARAUJO, A. C. B. Efeito do pastoreio de ovinos sobre a estrutura da mata ciliar do Arroio Espinilho em Santana do Livramento, RS, Brasil. 2010. 93 f. Dissertação (Mestrado em Silvicultura) Universidade Federal de Santa Maria, Santa Maria. 2010.

BARBOSA, L. M. Implantação de mata ciliar. In: SIMPOSIO MATA CILIAR: CIÊNCIA E TECNOLOGIA, 1999, Belo Horizonte. Trabalhos... Belo Horizonte: SMCCT, 1999. p. 35-111.

CARVALHO, C. G. Mato Grosso: terra e povo - um estudo de geo-história. Cuiabá: Edições Verde Pantanal, 2001. 208 p.

COSTA, P.; OLIVEIRA-FILHO, D.; MENÃO, D. Avaliação das áreas de preservação permanente ao longo dos cursos hídricos e nascentes em bacia de manancial, Ciência e Natura, Santa Maria, v. 32, n. 2, p. 197-209, 2011.

CUNHA, A. M.; LANI, J. L.; AMARAL, E. F.; REZENDE, S. B.; RIBEIRO, L. S. Mosaico digital de aerofotos não-convencionais na avaliação de recursos naturais: Estudo de caso. Revista Brasileira de Engenharia Agrícola e Ambiental, Campina Grande, v. 10, n. 1, p. 182-187, 2006.

CUNHA, M. A. Ocupação de encostas. São Paulo: Instituto Pesquisas Tecnológicas, 1991. 223 p.

DIAS, J. D.; GOMES, O. V. D; GOES, M. H. B. Áreas de riscos de erosão do solo: uma aplicação por geoprocessamento. Floresta e Ambiente, Seropédica, v. 8, p. 1-10, 2001.

DURIGAN, G.; RATTER, J. A. Successional changes in Cerrado and Cerrado/Forest Ecotonal vegetation in western São Paulo State, Brazil. Edinburgh Journal of Botany, Edinburgh, v. 63, p. 119130,2006
HABERLAND, N. T.; SILVA, F. C. B.; OLIVEIRA-FILHO, P. C.; VIDAL; C. M. S.; CAVALLIN, G. S. Análise da influência antrópica na qualidade da água do trecho urbano do rio das antas na cidade de Irati, Paraná. Revista Tecnológica, Maringá, v. 21, p. 53-67, 2012.

HORN, H. S. The ecology of secondary succession. Annual Reviews of Ecology and Systematics, Princeton, v. 5, p. 25-37, 1974.

LACERDA, D. M. A.; FIGUEIREDO, P. S. Restauração de matas ciliares do Rio Mearim no município de Barra do Corda-MA: seleção de espécies e comparação de metodologias de reflorestamento. Acta Amazônica, Manaus, v. 39, n. 2, p. 295-304, 2009.

LIMA, J. E. F. W.; SILVA, E. M. Recursos hídricos do Bioma Cerrado importância e situação. In: SANO, S. M.; ALMEIDA, S. P.; RIBEIRO, J. F. (Ed.). Cerrado ecologia e flora. 1 ed. Brasília: Embrapa Cerrados, 2008. p. 90-106.

LOZINSKI, M. A.; BALBINOT, R.; VENÂNCIO, D.; COSTA, P.; FILHO, D. O.; SCHIRMER, W. N. Diagnóstico das áreas de preservação permanente de nascentes na área urbana do município de Irati - PR. Floresta, Curitiba, v. 40, n. 1, p. 63-70, 2010.

MEDAUAR, O. Coletânea de legislação ambiental, Constituição Federal. São Paulo: Revista dos Tribunais, 2009. 1168 p.

MELO, C. E.; LIMA, J. D.; MELO, T. L.; PINTO-SILVA, V. Peixes do Rio das Mortes: identificação e ecologia das espécies mais comuns. Cáceres: Central de texto/UNEMAT, 2005. 146 p.

MENDES-JÚNIOR, C. W.; AYUP-ZOUAIN, R. N. Expansão da ocupação urbana de Gramado: estudo de caso da aplicação de fotografias aéreas de pequeno formato e SIG. Revista Pesquisas em Geociências, Porto Alegre, v. 31, n. 2, p. 3-14, 2004.

MMA - MINISTERIO DO MEIO AMBIENTE. Caderno da região hidrográfica do Tocantins-Araguaia. 2006. Brasília: MMA. Disponível em: <http:/www.mma.gov.br/estruturas/161/ publicacao/161_Publicação02032011035943.pdf $>$. Acesso em: $2 \overline{3}$ abr. 2012.

OLIVEIRA, E. C. L.; FELFILI, J. M. Estrutura e dinâmica da regeneração natural de uma mata de galeria no Distrito Federal, Brasil. Acta Botânica Brasílica, Feira de Santana, v. 19, n. 4, p. 801-811, 2005.

PIAIA, I. I. Geografia de Mato Grosso. Cuiabá: EDUNIC, 1999. $207 \mathrm{p}$.

RODRIGUES, R. R.; LEITÃO FILHO, H. F. Matas ciliares: conservação e recuperação. São Paulo: EDUSP/FAPESP, p. 320. 2000.

SEPLAN. Anuário Estatístico de Mato Grosso 2010. Vol. 32. Cuiabá: Secretaria de Estado de Planejamento e Coordenação Geral, 2010. 566 p.

SILVA, E. F.; MELO, C. E.; VENERE, P. C. Fatores que influenciam a comunidade de peixes em dois ambientes no baixo Rio das Mortes, Planície do Bananal, Mato Grosso, Brasil. Revista Brasileira de Zoologia, Curitiba, v. 24, n. 2, p. 482-492, 2007.

UNESCO. Vegetação no Distrito Federal - tempo e espaço. Uma avaliação multitemporal da perda de cobertura vegetal no DF e da Diversidade Floristica da Reserva da Biofera do Cerrado, fase 1. Brasília: Unesco, 2000. 55 p.

YARRANTON, G. A.; MORRISON, R. G. Spatial dynamics of a primary succession: Nucleation. The Journal of Ecology, London, v. 62, n. 2, p. 417-428, 1974.

ZAR, J. H. Biostatistical analysis. New Jersey: Prentice Hall, 1999. $663 \mathrm{p}$. 